OPEN ACCESS

Edited by:

Eli Hershkovitz,

Soroka Medical Center, Israel

Reviewed by:

George Arthur Werther,

Royal Children's Hospital, Australia

Serap Demirciog/u Turan,

Marmara University, Turkey

*Correspondence:

Huijuan Zhu

shengxin2004@163.com

Hui Pan

panhui201111111@163.com

${ }^{\dagger}$ These authors have contributed equally to this work

Specialty section:

This article was submitted to

Pediatric Endocrinology,

a section of the journal

Frontiers in Endocrinology

Received: 14 September 2021 Accepted: 17 November 2021 Published: 09 December 2021

Citation:

Liu S, Chen M, Yang H, Chen S, Wang L, Duan L, Zhu H and Pan H

(2021) Clinical Characteristics and

Long-Term Recombinant Human

Growth Hormone Treatment of 18q-

Syndrome: A Case Report and

Literature Review.

Front. Endocrinol. 12:776835.

doi: 10.3389/fendo.2021.776835

\section{Clinical Characteristics and Long-Term Recombinant Human Growth Hormone Treatment of 18q-Syndrome: A Case Report and Literature Review}

\author{
Shanshan Liu ${ }^{\dagger}$, Meiping Chen ${ }^{\dagger}$, Hongbo Yang, Shi Chen, Linjie Wang, Lian Duan, \\ Huijuan Zhu* and Hui Pan* \\ Key Laboratory of Endocrinology of National Health Commission, Department of Endocrinology, State Key Laboratory of \\ Complex Severe and Rare Diseases Peking Union Medical College Hospital, Chinese Academy of Medical Science and \\ Peking Union Medical College, Beijing, China
}

Background: $18 q$ - syndrome is a rare chromosomal disease caused by the deletion of the long arm of chromosome 18. Some cases with 18q- syndrome can be combined with growth hormone deficiency (GHD), but data on the efficacy of recombinant human growth hormone (rhGH) treatment in 18q- syndrome are limited.

Methods: Here, we report one case of 18q- syndrome successfully treated with longterm rhGH supplement. Previously reported cases in the literature are also reviewed to investigate the karyotype-phenotype relationship and their therapeutic response to $\mathrm{rhGH}$.

Results: A 7.9-year-old girl was referred for evaluation for short stature. Physical exam revealed proportionally short stature with a height of $111.10 \mathrm{~cm}(-3.02 \mathrm{SD}$ score (SDS)), low-set ears, a high-arched palate, a small jaw, webbed neck, widely spaced nipples, long and tapering fingers, and cubitus valgus. Thyroid function test indicated subclinical hypothyroidism. The peak value of growth hormone was $10.26 \mathrm{ng} / \mathrm{ml}$ in the levodopa provocation test. Insulin-like growth factor 1 (IGF-1) was $126 \mathrm{ng} / \mathrm{ml}$ (57-316 ng/ml). Other laboratory investigations, including complete blood cell count, liver and kidney function, gonadal function, serum adrenocorticotropin levels, and serum cortisol levels, were all within normal ranges. Karyotype analysis showed 46, XX, del (18) (q21). L-Thyroxine replacement and $\mathrm{rhGH}$ treatment were initiated and maintained in the following 7 years. At the age of 14.8 , her height has reached $159.5 \mathrm{~cm}$ with a height SDS increase of 2.82 SDS (from -3.02 SDS to -0.20 SDS). No significant side effects were found during the treatment. The literature review indicated the average rhGH treatment duration of 16 patients was $5.9 \pm 3.3$ years, and the average height SDS significantly increased from $-3.12 \pm 0.94$ SDS to $-1.38 \pm 1.29$ SDS after the rhGH treatment $(p<0.0001)$.

Conclusion: The main clinical manifestations of $18 q$ - syndrome include characteristic appearance, intellectual disability, and abnormal genital development. The literature review suggested a significant height benefit for short stature with 18q- syndrome from long-term rhGH treatment.

Keywords: 18q- syndrome, clinical characteristic, short stature, growth hormone deficiency, rhGH treatment 


\section{INTRODUCTION}

Chromosome 18q- syndrome (OMIM\# 601808) is a rare chromosomal disease, which was first reported by De Grouchy in 1964, and more than 100 cases had been reported to date (1). Previous studies suggested a distal critical region located in 18q22.3-23 (67.7-74.9 basis) and a proximal critical region located in 18q12.1-q12.3 (25.2-42.9 basis) (2). The most common cause of the syndrome is the deletion of the terminal of the long arm of chromosome 18 (3). The clinical phenotypes of $18 \mathrm{q}$ - syndrome are highly variable due to heterogeneity with variable size and genetic content and imbalances from structurally abnormal chromosomes. Commonly reported phenotypic features of 18q- syndrome are as follows: 1) physical deformities including mid-face dysplasia, ear canal deformity, hand or foot abnormalities, and genital dysplasia; 2) psychoneurological abnormalities including intellectual disability, hypotonia, language and motor development delay, and hearing impairment; 3 ) and short stature with or without growth hormone deficiency (GHD) (4). Short stature is a common and important issue in patients with 18q- syndrome, and concurrence of GHD had been reported in some of these patients (5-7). However, information about the efficacy of recombinant human growth hormone (rhGH) treatment in patients with $18 \mathrm{q}$ - syndrome is limited.

Here, we report a case with 18q- syndrome who was successfully treated with long-term rhGH supplement. Previously reported cases in the literature are also reviewed to investigate the karyotype-phenotype relationship and their therapeutic response to rhGH.

\section{MATERIALS AND METHODS}

\section{Participant}

In this study, the patient underwent physical examination and laboratory investigations for evaluation of short stature. Complete blood cell count, liver and kidney function, thyroid function, gonadal function, serum adrenocorticotropin levels and serum cortisol levels, serum insulin-like growth factor-1 (IGF-1) levels, and GH stimulation tests were all tested in the central laboratory of Peking Union Medical College Hospital. In the levodopa growth hormone provocation test, changes in $\mathrm{GH}$ levels were monitored in blood samples collected before medication and 30,60,90, and 120 min following levodopa administration. Peak GH of less than $10 \mathrm{ng} / \mathrm{ml}$ was adopted for the diagnosis of pediatric GHD in this study. Bone age was assessed using the G\&P and TW3 methods (8).

Clinical information on the first and follow-up visits was collected, including birth history, history of growth and development, physical examination, laboratory, and radiological data.

\section{Literature Review}

We searched for all articles in English on 18q- syndrome published up to May 2021, in which diagnosis of 18q- syndrome was confirmed by karyotype and clinical characters were described. Duplicated cases from the same research group were excluded.
Clinical data, karyotypes, and rhGH treatment were recorded and summarized.

\section{Statistical Analysis}

Statistical analysis was performed using SPSS.25 software. Continuous variables were expressed as the mean $\pm \mathrm{SD}$ statement. A paired-samples t-test was used to compare the variables before and after the rhGH treatment. A p-value of less than 0.05 was considered statistically significant.

\section{RESULTS}

\section{Case Present}

A 7.9-year-old girl was referred to our clinic for evaluation of short stature. She was the first child of healthy, nonconsanguineous parents. She was born at term by cesarean section because of breech presentation. Her birth weight was $2.75 \mathrm{~kg}(-2.00 \mathrm{SD}$ to $-1.00 \mathrm{SD})$, and her birth length was $46 \mathrm{~cm}$ $(<-2.00 \mathrm{SD})$. The height of her father and mother were $177 \mathrm{~cm}$ $(+0.71$ SD score (SDS)) and $163 \mathrm{~cm}(+0.45 \mathrm{SDS})$, respectively, with a mid-parental height (MPH) of $163.5 \mathrm{~cm}$. She presented abnormal sucking at birth and mild intellectual disability from childhood. Due to poor coordination and inattention, artificial feeding was performed up to 4 years old.

Physical examination at the first evaluation revealed her height was $111.1 \mathrm{~cm}(-3.02 \mathrm{SDS})$ and weight was $19 \mathrm{~kg}(-1.46 \mathrm{SDS})$. She had low-set ears, a high-arched palate, a small jaw, webbed neck, widely spaced nipples, long and tapering fingers, and cubitus valgus. The thyroid gland was non-palpable. The peak value of growth hormone was $10.26 \mathrm{ng} / \mathrm{ml}$ in the levodopa growth hormone provocation test. IGF-1 was $126 \mathrm{ng} / \mathrm{ml}(57-316 \mathrm{ng} / \mathrm{ml})$. Thyrotropin (TSH) level was $6.62 \mu \mathrm{IU} / \mathrm{ml}(0.38-4.34)$, free triiodothyronine (FT3) was $4.10 \mathrm{pg} / \mathrm{ml}(1.80-4.10)$, and free thyroxine (FT4) was $1.51 \mathrm{ng} / \mathrm{dl}$ (0.81-1.89). Anti-thyroid peroxidase and anti-thyroglobulin levels were all in normal ranges. Other laboratory investigations, including complete blood cell count, liver and kidney function, gonadal function, serum adrenocorticotropin levels, and serum cortisol levels, were all in normal ranges. The initial bone age was consistent with chronological age. Karyotype analysis showed 46, XX, del (18) (q21).

L-Thyroxine (L-T4) replacement therapy and rhGH treatment were initiated. rhGH was started at $0.05 \mathrm{mg} / \mathrm{kg} / \mathrm{day}$ and titrated gradually during follow-up, with an average dose of about $0.06 \mathrm{mg} / \mathrm{kg} / \mathrm{day}$. She has been treated for 7 years, and her compliance was good. Her height reached $159.5 \mathrm{~cm}(-0.20$ SDS) at 14 years 8 months. During rhGH treatment, the growth velocity (GV) was $8.3 \mathrm{~cm} /$ year in the first year and $7.8 \mathrm{~cm} /$ year in the second year (Figure 1). Bone age was consistent with chronological age. She presented with normal onset of puberty and menarche at 14 years. There were no serious adverse reactions during long-term rhGH treatment.

\section{Phenotype Summaries of 18q- Syndrome in Literature Review}

There were 162 eligible cases of 18q- syndrome enrolled in the study. Including the present case, a total of 163 cases were 


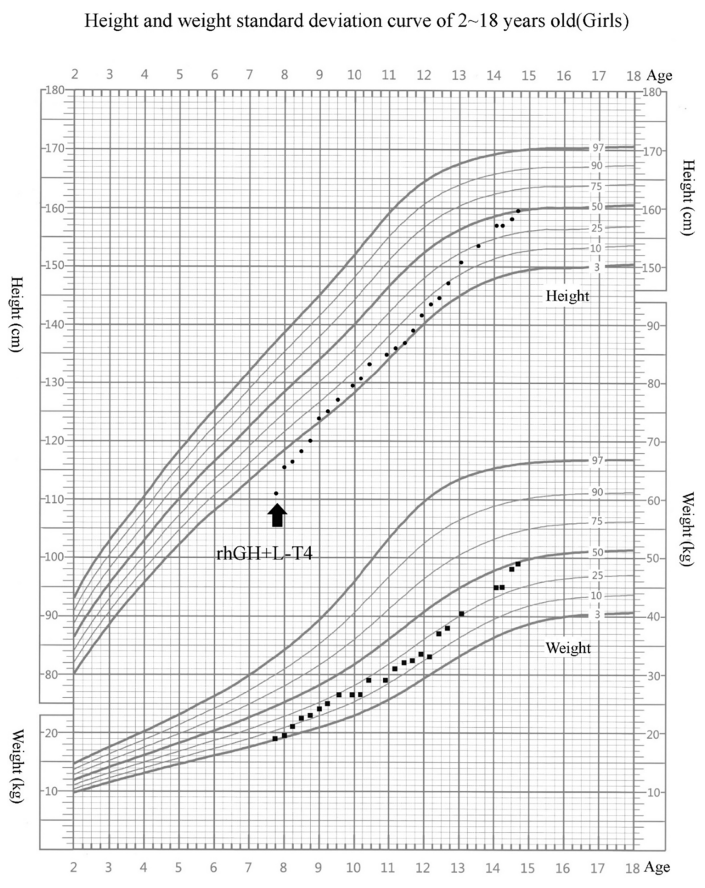

FIGURE 1 | Growth chart of our patient. Arrow indicates the inception of recombinant human growth hormone ( $\mathrm{rGH}$ ) treatment. The girl's growth curve significantly improved with $\mathrm{GH}$ treatment over time. Height curve, circles; weight curve, squares.

recorded and summarized. The median age was 5.75 years (ranging from 2.90 to 12.06 years), the average height SDS was $-2.04 \pm 1.36$, and the average weight SDS was $-1.01 \pm 1.68$. The clinical manifestations are summarized in Figure 2. The main features include the following: 1) physical deformities including ear abnormality (ear canal stenosis, hearing impairment, prominent antihelix, and antitragus) (65.6\%), mid-face dysplasia (47.2\%), abnormal hands (aschistodactylia, tapering fingers, clinodactylism, proximally implanted thumbs, excess whorls, and "simian-variant" palmar creases) (41.1\%), abnormal feet (varus deformity, dactylion, and abnormal toes) (39.3\%), short stature (35.0\%), ocular abnormality (strabismus, corneal opacification, cataracts, glaucoma, optic atrophy, and nystagmus) (32.5\%), abnormal genital development (blind uterine horns, uterine remnant, and absence of vagina/cervix) (28.2\%), carp mouth (28.2\%), congenital heart disease (19.0\%), microcephaly (17.2\%), epicanthus (16.0\%), a high-arched palate (13.5\%), a cleft palate (11.0\%), urinary system abnormality (hypospadias, renal insufficiency, horseshoe kidney, and uronephrosis) (9.8\%), skin disease (eczema, vitiligo, and atopic dermatitis) (6.7\%), and short neck (5.5\%); 2) psychoneurological abnormalities including intellectual disability (57.1\%), language and motor development delay (49.7\%), hypotonia (40.5\%), delayed myelination (10.4\%), and autism (6.7\%); and 3) IgA deficiency (4.3\%) and hypothyroidism (3.7\%).

\section{Summaries of Karyotypes}

There were 119 cases reported with detailed karyotype descriptions, including 104 cases of terminal fragment deletions and 15 cases of interstitial deletions of the long arm of chromosome 18 (Figure 3). The chromosome fragment deletions mainly occurred in the 18q23 (87.4\%), followed by the $18 \mathrm{q} 22.3-\mathrm{q} 23(84.9 \%)$. As for cases with short stature, the chromosome fragment deletions mainly occurred in the $18 \mathrm{q} 23$ (90.0\%), followed by the 18q22.3-q23 (84.0\%).

\section{Recombinant Human Growth Hormone Treatment in Patients With 18q- Syndrome}

Twenty-two patients with $18 \mathrm{q}$ - syndrome in the literature and our present case received $\mathrm{rhGH}$ treatment. Six cases were excluded from the analysis because of missing treatment

Clinical findings in the $18 \mathrm{q}$ - syndrome

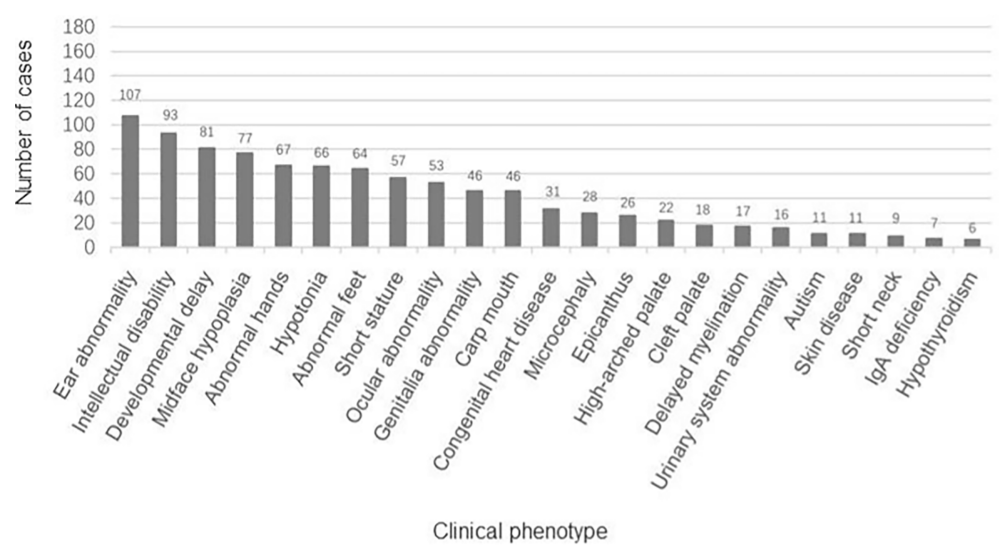

FIGURE 2 | Clinical findings in the 163 patients with 18q- syndrome. 


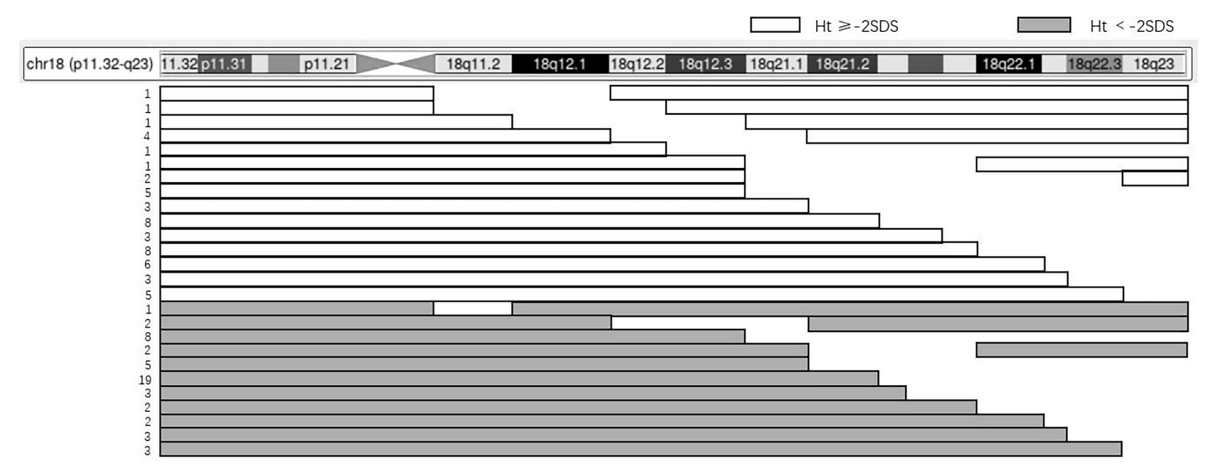

FIGURE 3 | The relation between karyotype and height of 119 patients. The panel illustrates the chromosome content for 119 patients with an $18 q$ deletion and short stature using the UCSC Genome Browser Custom Tracks feature. The horizontal bars depict the region of chromosome 18, while the gaps indicate the hemizygous region. The number of patients that have the same karyotype is shown on the left.

information. Thus, a total of 16 cases had been summarized in the study. As shown in Table $\mathbf{1}$, the average age of initial treatment was $3.70 \pm 2.90$ years, the average treatment duration was $5.90 \pm 3.30$ years, and the average height SDS was significantly increased from $-3.12 \pm 0.94$ to $-1.38 \pm 1.29$ ( $\mathrm{p}<$ 0.0001) (Figure S1). Among these cases, 13 were reported from the University of Texas Health Science Center. The average dose of $\mathrm{rhGH}$ was $0.3 \mathrm{mg} / \mathrm{kg} /$ week, the average treatment duration was $6.00 \pm 3.20$ years, and the average height SDS increase was 1.80 (9).

\section{DISCUSSION}

Here, we reported one case of 18q- syndrome successfully treated with long-term rhGH supplement. All previously reported cases in the literature were also reviewed to investigate the karyotype-phenotype relationship and their therapeutic response to $\mathrm{rhGH}$. The phenotype of $18 \mathrm{q}-$ syndrome was highly variable characterized by short stature, intellectual disability, and multisystem organ involvement. The literature review suggested a significant height benefit for short stature with $18 \mathrm{q}$ - syndrome from long-term rhGH treatment.

The clinical manifestations of 18q- syndrome were complex and diverse, and it was difficult to establish an accurate relationship between genotype and phenotype. There were two main concerns in the karyotype-phenotype relationship: 1) no consistency between the deletion and phenotype had been found in this review of data. The most common cause of the syndrome was the terminal deletion of the long arm of chromosome $18(87.4 \%)$, and the interstitial deletion was rare $(12.6 \%)$. We compared the clinical characteristics of patients with interstitial deletion and terminal deletion and found that no significant difference existed between these two groups of patients, which was

TABLE 1 | Summary of the relevant literature on rhGH treatment for short stature of 18q- syndrome.

\begin{tabular}{|c|c|c|c|c|c|c|c|}
\hline Reference & Gender & Age & Dose & Duration (years) & Height SDS before treatment & Height SDS after treatment & $\Delta \mathrm{HT}$ SDS \\
\hline Our center & $\mathrm{F}$ & $93 m$ & 0.06 mg/kg/day & 7 & -3.02 & -0.20 & 2.82 \\
\hline \multirow[t]{13}{*}{ Cody, J D (9) } & NA & $13 m$ & $0.30 \mathrm{mg} / \mathrm{kg} /$ week & $6.00 \pm 3.20$ & -3.11 & +0.85 & 3.96 \\
\hline & NA & $35 \mathrm{~m}$ & $0.30 \mathrm{mg} / \mathrm{kg} /$ week & & -3.58 & -1.55 & 2.03 \\
\hline & NA & $33 m$ & $0.30 \mathrm{mg} / \mathrm{kg} /$ week & & -2.16 & +0.45 & 2.61 \\
\hline & NA & $81 \mathrm{~m}$ & $0.30 \mathrm{mg} / \mathrm{kg} /$ week & & -4.79 & -2.15 & 2.64 \\
\hline & NA & $35 \mathrm{~m}$ & $0.30 \mathrm{mg} / \mathrm{kg} /$ week & & -2.37 & -1.10 & 1.27 \\
\hline & NA & $20 m$ & $0.30 \mathrm{mg} / \mathrm{kg} /$ week & & -2.21 & -0.65 & 1.56 \\
\hline & NA & $31 \mathrm{~m}$ & $0.30 \mathrm{mg} / \mathrm{kg} /$ week & & -4.11 & -2.50 & 1.61 \\
\hline & NA & $56 m$ & $0.30 \mathrm{mg} / \mathrm{kg} /$ week & & -2.05 & -2.06 & -0.01 \\
\hline & NA & $46 m$ & $0.30 \mathrm{mg} / \mathrm{kg} /$ week & & -1.66 & -1.66 & 0 \\
\hline & NA & $64 m$ & $0.30 \mathrm{mg} / \mathrm{kg} /$ week & & -2.59 & -0.30 & 2.29 \\
\hline & NA & $5 \mathrm{~m}$ & $0.30 \mathrm{mg} / \mathrm{kg} /$ week & & -4.20 & -3.05 & 1.15 \\
\hline & NA & $9 m$ & $0.30 \mathrm{mg} / \mathrm{kg} /$ week & & -2.60 & -1.70 & 0.90 \\
\hline & NA & $31 \mathrm{~m}$ & $0.30 \mathrm{mg} / \mathrm{kg} /$ week & & -3.30 & -0.40 & 2.90 \\
\hline Jackowski, T (10) & $\mathrm{F}$ & $20 \mathrm{~m}$ & 0.30 mg/kg/day & 8 & -4.12 & -2.03 & 2.09 \\
\hline Schwarz, H (7) & $\mathrm{F}$ & $136 \mathrm{~m}$ & $2.50 \mathrm{mg} / \mathrm{qod}$ & 1 & -4.02 & -3.98 & 0.04 \\
\hline Mean & & $3.70 \pm 2.90$ years & & $5.90 \pm 3.30$ years & $-3.12 \pm 0.94$ & $-1.38 \pm 1.29$ & $1.74 \pm 1.15$ \\
\hline
\end{tabular}

$N A$, not available; $r h G H$, recombinant human growth hormone; SDS, SD score; HT, height; $m$, months. 
consistent with a previous report (11). 2) There was no absolute correlation between the size of deletions and phenotype, which was also consistent with a previous report (12). A case with 21.77-Mb deletion (18q21.32-q23) was characterized by a range of physical deformities including microcephaly, middle facial dysplasia, cleft lip and palate, slender fingers, atrial septal defect and moderate pulmonary artery stenosis, intellectual disability, intellectual disability, otitis media, and eczema (10). Another case with 34.47-Mb deletion (18q21.1-q23) presented with fewer physical deformities (12). Differences of phenotypes had been reported in family members with the same karyotype with 18q- syndrome (13). However, Kline et al. established a correlation between the size of deletion and clinical severity by array comparative genomic hybridization (CGH) (14). Further investigations are needed to confirm this correlation in a larger cohort. Further studies are also needed to evaluate the important genes that may be involved in the pathogenesis, including SS18 gene (15), CYB5A gene (16), and Sall3 or Tshzl gene (17), which play key roles in long bone development, gonadogenesis, and development of skull and midline structures.

Short stature is a common issue in the management of $18 \mathrm{q}-$ syndrome. Of the reported cases, 35.0\% had short stature. There are many reasons for short stature in patients with $18 \mathrm{q}$ syndrome. First, GHD is the main concern in previously reported cases with short stature (18). Our case had prominent short stature with no GHD. More data are needed to assess the status of growth hormone secretion in this group of rare diseases. Second, hypothyroidism is an important contributing factor in short stature. Cases with hypothyroidism had prominent short stature (mean height $-2.90 \pm 0.80$ ). Shaub et al. reported that the critical region for hypothyroidism was located at the terminal of $18 \mathrm{q}$ with the deletion of $13.3 \mathrm{Mb}$ (19). Thyroid hormones are key regulators of bone homeostasis and skeletal development (20). Routine screening for thyroid function could be very beneficial for the management of 18- syndrome, and that thyroid hormone supplementation should be promptly administered to $18 \mathrm{q}-$ syndrome with hypothyroidism. Thirdly, important genes on chromosome 18 are effectively involved in the pathogenesis of short stature. In 2009, Cody et al. found that the crucial area was located at 18q22.3-q23 for patients with short stature (21). The myelin basic protein (MBP) gene and the galanin receptor 1 (GALR1) gene are located at 18q23 and are considered to be the main candidate genes for short stature (22). The lack of $18 \mathrm{q} 23$ may lead to haplotype insufficiency of $M B P . M B P$ is the main component of myelin in the central nervous system. Myelin development disorders are considered to have the same critical area as short stature. The propane receptor is a $G$ proteincoupled receptor, ligand of propane is a neuromodulator that is expressed in the central and peripheral nervous system, and it stimulates GH secretion by interacting with specific membrane receptors. But not all missing genes have a phenotype of short stature when hemizygous, and perhaps environmental factors or genes on other chromosomal regions are modulating the phenotype.
The data of rhGH treatment in 18q- patients are limited. In our patient, long-term rhGH treatment successfully increased height SDS, and no obvious side effects had been found. The height of all 16 patients we reviewed had increased by 1.78 SDS after an average treatment duration of 5.90 years. In addition, previous studies have demonstrated that $\mathrm{GH}$ treatment had beneficial effects on performance IQ and myelination $(9,22)$. Multicenter registration researches are needed to further confirm the safety and efficacy of $\mathrm{rhGH}$ in the treatment of this rare syndrome.

However, there are potential limitations in this study. First, the sample size was relatively small. Additionally, the lack of detailed information on previously reported cases is a further limitation. Further research is still needed in the future. Another limitation is the lack of assessment and the evolution of diagnostic criteria for GHD.

\section{CONCLUSION}

The clinical phenotypes of $18 \mathrm{q}-$ syndrome are highly variable. Routine physical examination, laboratory investigations, and chromosome screening may facilitate the early diagnosis and treatment of the disease. In addition, the literature review suggested that long-term treatment of growth hormone is effective, and further research is still needed in the future.

\section{PATIENT'S PERSPECTIVE}

The patient: "After rhGH treatment, my appetite slightly increased and my height successfully improved, I'm very satisfied".

\section{DATA AVAILABILITY STATEMENT}

The raw data supporting the conclusions of this article will be made available by the authors, without undue reservation.

\section{ETHICS STATEMENT}

The studies involving human participants were reviewed and approved by the ethics committee of the Peking Union Medical College Hospital. Written informed consent to participate in this study was provided by the participants' legal guardian/next of kin.

\section{AUTHOR CONTRIBUTIONS}

HP and HZ designed the study. SL collected the data. SL and MC drafted the manuscript. HY guided the writing of the article. HY, SC, LW, LD, HZ, and HP interpreted the data and revised the manuscript. All authors contributed to the article and approved the submitted version. 


\section{FUNDING}

This study was supported by CAMS Innovation Fund for Medical Science (CIFMS-2016-I2M-1-008) and the National Natural Science Foundation of China (No. 81673184).

\section{REFERENCES}

1. De Grouchy J, Royer P, Salmon C, Lamy M. Partial Deletion Of The Long Arms Of The Chromosome 18. Pathol biol (1964) 12:579-82.

2. Feenstra I, Vissers LE, Orsel M, van Kessel AG, Brunner HG, Veltman JA, et al. Genotype-Phenotype Mapping of Chromosome 18q Deletions by HighResolution Array CGH: An Update of the Phenotypic Map. Am J Med Genet A (2007) 143a:1858-67. doi: 10.1002/ajmg.a.31850

3. Cody JD, Pierce JF, Brkanac Z, Plaetke R, Ghidoni PD, Kaye CI, et al. Preferential Loss of the Paternal Alleles in the 18q- Syndrome. Am J Med Genet (1997) 69:280-6. doi: 10.1002/(SICI)1096-8628(19970331)69:3<280:: AID-AJMG12>3.0.CO;2-N

4. Cody JD, Hasi M, Soileau B, Heard P, Carter E, Sebold C, et al. Establishing a Reference Group for Distal 18q-: Clinical Description and Molecular Basis. Hum Genet (2014) 133:199-209. doi: 10.1007/s00439-013-1364-6

5. Budisteanu M, Arghir A, Chirieac SM, Tutulan-Cunita A, Lungeanu A. 18q Deletion Syndrome - A Case Report. Maedica (2010) 5:135-8.

6. Hale DE, Cody JD, Baillargeon J, Schaub R, Danney MM, Leach RJ. The Spectrum of Growth Abnormalities in Children With 18q Deletions. J Clin Endocrinol Metab (2000) 85:4450-4. doi: 10.1210/jc.85.12.4450

7. Schwarz H, Duck SC. Growth Hormone Deficiency in Children With Chromosomal Abnormalities. Arch Dis Child (1990) 65:334. doi: 10.1136/ adc.65.3.334-a

8. Park K, Kim J, Sung S, Lee M, Song HJ. Assessment of Skeletal Age in Multiple Epiphyseal Dysplasia. J Pediatr Orthop (2014) 34:738-42. doi: 10.1097/ BPO.0000000000000172

9. Cody JD, Semrud-Clikeman M, Hardies LJ, Lancaster J, Ghidoni PD, Schaub RL, et al. Growth Hormone Benefits Children With 18q Deletions. Am J Med Genet A (2005) 137:9-15. doi: 10.1002/ajmg.a.30848

10. Jackowski T, Petriczko E, Horodnicka-Jozwa A, Biczysko-Mokosa A, Szalecki M, Walczak M. Growth Hormone Treatment in a Patient With Deletion of the Long Arm of Chromosome 18: An 8-Year Observation. Neuro Endocrinol Lett (2019) 40:169-74.

11. Kato Z, Morimoto W, Kimura T, Matsushima A, Kondo N. Interstitial Deletion of 18q: Comparative Genomic Hybridization Array Analysis of 46, XX,del(18)(q21.2.q21.33). Birth Defects Research. Part A Clin Mol Teratol (2010) 88:132-5. doi: 10.1002/bdra.20633

12. Wilson M, Towner J, Forsman I, Siris E. Syndromes Associated With Deletion of the Long Arm of Chromosome 18[Del(18q)]. Am J Med Genet (1979) 3:155-74. doi: 10.1002/ajmg.1320030207

13. Margarit E, Morales C, Rodríguez-Revenga L, Monné R, Badenas C, Soler A, et al. Familial $4.8 \mathrm{MB}$ Deletion on 18q23 Associated With Growth Hormone Insufficiency and Phenotypic Variability. Am J Med Genet A (2012) 158a:611-6. doi: 10.1002/ajmg.a.34221

14. Kline AD, White ME, Wapner R, Rojas K, Biesecker LG, Kamholz J, et al. Molecular Analysis of the 18q- Syndrome-and Correlation With Phenotype. Am J Hum Genet (1993) 52:895-906.

\section{SUPPLEMENTARY MATERIAL}

The Supplementary Material for this article can be found online at: https://www.frontiersin.org/articles/10.3389/fendo.2021. 776835/full\#supplementary-material

15. de Bruijn D, Peters W, Chuva de Sousa Lopes S, van Dijk A, Willemse M, Pfundt R, et al. Targeted Disruption of the Synovial Sarcoma-Associated SS18 Gene Causes Early Embryonic Lethality and Affects PPARBP Expression. Hum Mol Genet (2006) 15:2936-44. doi: 10.1093/hmg/ ddl235

16. Idkowiak J, Randell T, Dhir V, Patel P, Shackleton C, Taylor N, et al. A Missense Mutation in the Human Cytochrome B5 Gene Causes 46,XY Disorder of Sex Development Due to True Isolated 17,20 Lyase Deficiency. J Clin Endocrinol Metab (2012) 97:E465-75. doi: 10.1210/jc.2011-2413

17. Dostal A, Nemeckova J, Gaillyova R. The 18q Deletion Syndrome and Analysis of the Critical Region for Orofacial Cleft at $18 \mathrm{q} 22.3$. J Craniomaxillofac Surg (2009) 37:272-5. doi: 10.1016/j.jcms.2008.12.002

18. Cody JD, Hale DE, Brkanac Z, Kaye CI, Leach RJ. Growth Hormone Insufficiency Associated With Haploinsufficiency at 18q23. Am J Med Genet (1997) 71:420-5. doi: 10.1002/(SICI) 1096-8628(19970905)71:4<420::AIDAJMG9>3.0.CO;2-X

19. Schaub RL, Hale DE, Rose SR, Leach RJ, Cody JD. The Spectrum of Thyroid Abnormalities in Individuals With 18q Deletions. J Clin Endocrinol Metab (2005) 90:2259-63. doi: 10.1210/jc.2004-1630

20. Tsourdi E, Lademann F, Siggelkow HJDI. Impact of Thyroid Diseases on Bone. Internist (Berl) (2018) 59:661-7. doi: 10.1007/s00108-018-0436-Z

21. Cody JD, Heard PL, Crandall AC, Carter EM, Li J, Hardies LJ, et al. Narrowing Critical Regions and Determining Penetrance for Selected 18q- Phenotypes. Am J Med Genet A (2009) 149a:1421-30. doi: 10.1002/ajmg.a.32899

22. Cody JD, Sebold C, Heard P, Carter E, Soileau B, Hasi-Zogaj M, et al. Consequences of Chromsome18q Deletions. American Journal of Medical Genetics. Part C Semin Med Genet (2015) 169:265-80. doi: 10.1002/ ajmg.c.31446

Conflict of Interest: The authors declare that the research was conducted in the absence of any commercial or financial relationships that could be construed as a potential conflict of interest.

Publisher's Note: All claims expressed in this article are solely those of the authors and do not necessarily represent those of their affiliated organizations, or those of the publisher, the editors and the reviewers. Any product that may be evaluated in this article, or claim that may be made by its manufacturer, is not guaranteed or endorsed by the publisher.

Copyright (c) 2021 Liu, Chen, Yang, Chen, Wang, Duan, Zhu and Pan. This is an open-access article distributed under the terms of the Creative Commons Attribution License (CC BY). The use, distribution or reproduction in other forums is permitted, provided the original author(s) and the copyright owner(s) are credited and that the original publication in this journal is cited, in accordance with accepted academic practice. No use, distribution or reproduction is permitted which does not comply with these terms. 